\title{
HIV-I Subtype C, CCR5-using Viruses are Detected in CD4T Cells and Macrophages in South African AIDS Patients. Analysis by Fluorescent In Situ Hybridization and V3 Loop Sequencing Te-chang/Mike Lo* ${ }^{* \ddagger}$ and Pascale Willem
}

\author{
Address: Cytogenetic unit, Department of Molecular Medicine \& Haematology, Medical School, University of Witwatersrand, Johannesburg, South \\ Africa, 2000 \\ Email: Te-chang/Mike Lo* - mikelotc@gmail.com \\ * Corresponding author ‡Presenting author
}

from 2005 International Meeting of The Institute of Human Virology

Baltimore, USA, 29 August - 2 September 2005

Published: 8 December 2005

Retrovirology 2005, 2(Suppl I):P58 doi:10.1 186/1742-4690-2-SI-P58

\section{Background}

In South Africa, HIV-1 subtype C is the prevalent subtype and has been found to use CCR5 throughout the viral infection in most cases 1 . In contrast, HIV-1 subtype B often switches its coreceptor usage to CXCR4 due to mutations primarily within the V3 loop of the gp120 protein ${ }^{2}$. In order to assess whether subtype $\mathrm{C}$ is still able to infect $\mathrm{T}$ cells in late stages of the infection, FISH was used to localize HIV sequences within different blood cell types of AIDS patients.

\section{Methods and Materials}

Fresh blood and bone marrow samples obtained upon informed consent from late stage, antiretroviral therapynaïve, non-opportunistic infectious HIV patients were separated into CD4+ and CD4- fractions using Dynabeads. The cells were washed, placed onto slides, and hybridized with HIV-gag-RNA-specific probes, labelled by nick translation with spectrum green. Following overnight incubation at $37^{\circ} \mathrm{C}$, the slides were washed, stained with DAPI and analyzed under fluorescent microscopy. DNA was also extracted from each sample, the HIV envelope gene was amplified using nested primers, subjected to sequencing to determine the V3 loop sequence and the resulting overall positive charges.

\section{Results}

In order to assess the site of HIV subtype $\mathrm{C}$ active infection in late stage of the disease FISH was performed on peripheral blood or bone marrow slides of $20 \mathrm{HIV}^{+}$patients produced positive signals in and around the nucleus of CD4+ $\mathrm{T}$ cell as well as monocytes/macrophages, whereas control slides made from HIV- individuals and CD4- fractions of HIV patients possessed no signals. Both CD $4^{+}$cell population exhibited high number of signals, but the T cells had a greater variation, ranging from none to over thirty. The V3 loop sequencing and analysis of the protein sequence from 11 of the 20 patients revealed the structure's overall positive charge and amino acid placements were compatible with HIV-1 subtype C CCR5-using viruses in these patients.

\section{Conclusion}

Despite the use of CCR 5 by HIV-1 subtype C, CD4+ T cells were found to exhibit positive signals in vivo in late stage $\mathrm{HIV}^{+}$patients. This may suggest that CCR5 expression is upregulated on CD4v T cells to allow the virus access, or that the virus is exploiting some other mechanism of invasion like the viral synapses that has been found to exist between infected macrophages and uninfected $\mathrm{T}$ cells, rather than a direct approach of infection where the use of chemokine receptors are necessary.

\section{References}

I. Bredell H, Williamson C, Sonnenberg P, Martin DJ, Morris L: Genetic characterization of HIV type I from migrant workers in three South African gold mines. AIDS Res Hum Retroviruses 1998, I4(8):677-84.

2. Chan SY, Speck RF, Power C, Gaffen SL, Chesebro B, Goldsmith MA: $V 3$ recombinants indicate a central role for CCR5 as a coreceptor in tissue infection by human immunodeficiency virus type I. J Virol 1999, 3:2350-8. 